\title{
Eight and a Half Syndrome: A Rare Case of Pontine Infarction
}

\author{
Akkayasamy Kowsalya ${ }^{\otimes}$, Srinivasan Thanemozhi DO \\ Aravind Eye Hospital, India
}

\begin{abstract}
Introduction: This case report describes “one-and-a-half” syndrome with supranuclear facial palsy.

Case: 39 years old male hypertensive patient presented with right facial nerve palsy, internuclear ophthalmoplegia and conjugate gaze palsy. Neuroimaging showed acute posterior pontine infarct at medial longitudinal fasciculus, paramedian pontine reticular formation, abducens nerve nucleus and seventh nerve fascicular zone.

Observation: "One-and-a-half"syndrome is characterized by a lateral gaze palsy in one direction and internuclear ophthalmoplegia in the other. Our patient had Right sided one and a half syndrome along with the right facial nerve palsy.

Conclusion: Eight and a half syndrome is a rare manifestation of pontine infarction.

Key words: Eight and a half syndrome, Horizontal gaze palsy, Internuclear ophthalmoplegia, Pontine infarct.
\end{abstract}

\section{INTRODUCTION}

A remarkable disorder of eye movement consisting of lateral gaze palsy in one direction and internuclear ophthalmoplegia (INO) was described by Freeman et al. This was later coined as "one and a half syndrome" by Miller Fisher to describe a commixture of horizontal gaze palsy and INO caused by a lesion in paramedian pontine reticular formation (PPRF) and medial longitudinal fasciculus (MLF) respectively. The constellation of one- and-a half syndrome with seventh cranial nerve palsy was referred to as Eight-and-a-half syndrome by Eggenberger E (1998).

$\begin{array}{ll}\text { Financial Interest }: \text { Nil } & \text { Received : 14.09.2020 } \\ \text { Conflict of Interest : Nil } & \text { Accepted : 02.02.2021 } \\ \text { Corresponding Author } & \\ \text { Dr. Akkayasamy Kowsalya } & \\ \text { Aravind Eye Hospital, India. } & \\ \text { E-mail: kowsalyabalajigmail.com } & \end{array}$

Access this article online

Website: www.nepjol.info/index.php/NEPJOPH DOI: https://doi.org/10.3126/nepjoph.v13i2.31210 Copyright $\odot 2021$ Nepal Ophthalmic Society ISSN: 2072-6805, E-ISSN: 2091-0320

This work is licensed under a Creative Commons Attribution-NonCommercial-NoDerivatives 4.0 International License (CC BY-NC-ND). 


\section{CASE REPORT}

A 39-year-old male, chronic smoker, alcoholic and known hypertensive presented with a history of excess tearing from the right eye, drooling of saliva from the right side of mouth and blurred vision in both eyes for five days. Symptoms were of acute onset and non progressive. There was no history of headache, giddiness, pain or injury.

On examination, he had a deviation of the left angle of mouth (Figure 1a). Right eye showed lagophthalmos with poor bell's phenomenon and orbicularis weakness (Figure 1b), with best corrected visual acuity $6 / 6$ in both eyes. Anterior segment was otherwise normal. Restriction of abduction (-3) and adduction (-1) in the right eye and restriction of adduction (-3) with associated overaction of abduction $(+2)$ in the left eye with abducting nystagmus were noted. Examination of versions revealed right horizontal gaze palsy. Colour vision and central fields were normal in both eyes. Fundus was normal in both eyes. Central nervous system examination revealed normal higher functions along with $7^{\text {th }}$ cranial nerve palsy. Diagnosis of right lower motor neuron Facial nerve palsy with right Internuclear ophthalmoplegia (Figure 2a) and right horizontal gaze palsy (Figure $2 b$ ) was made, which is combinedly termed as Eight and a half syndrome. Routine serological examination results were normal. Magnetic Resonance Imaging (MRI) and Magnetic Resonance Angiogram (MRA) Brain, plain and

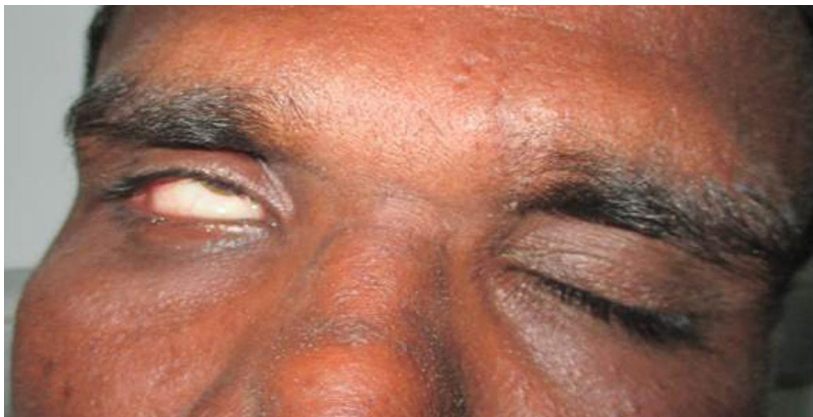

Fig 1A

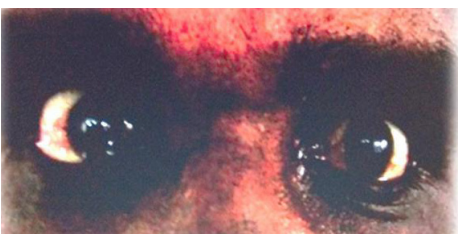

Fig $1 \mathrm{C}$

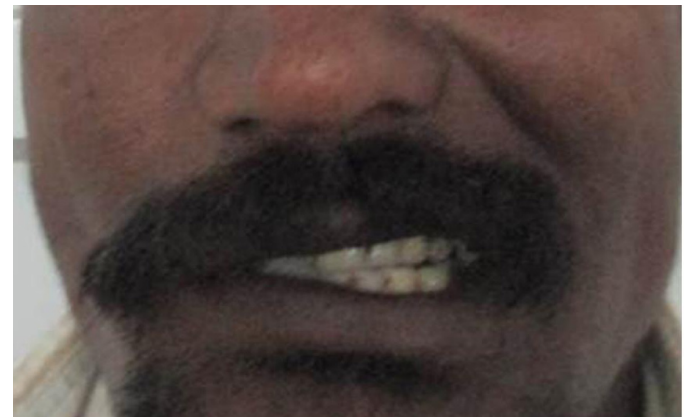

Fig 1B
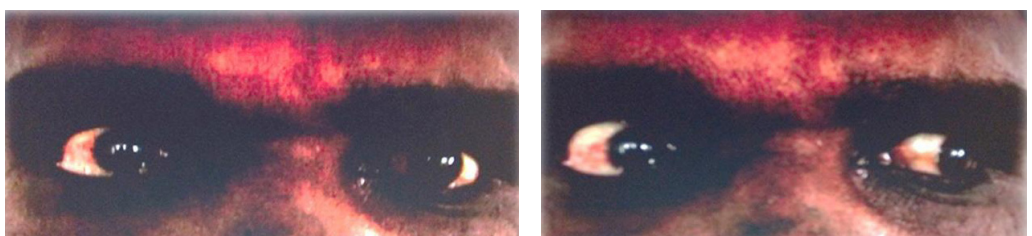

Fig 1D

Figure 1A: Lagophthalmos in the right eye; Figure 1B: Right facial nerve palsy; Figure 1C: Right horizontal gaze palsy; Figure 1D: Internuclear ophthalmoplegia in the right eye. 


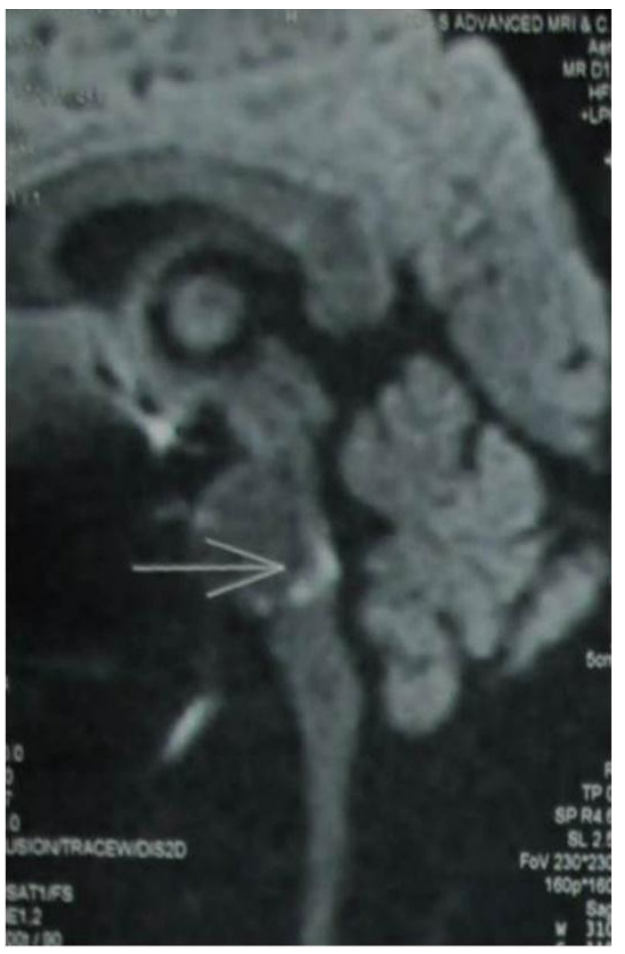

Fig 2A

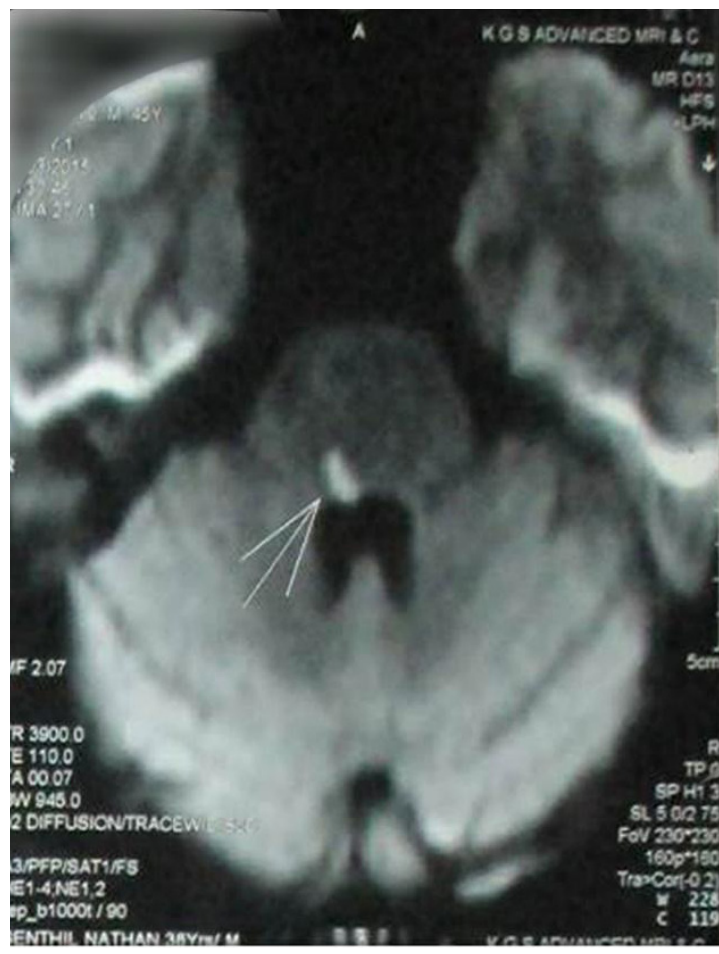

Fig 2B

Figure 2: Hyperintensity at the right posterior pons at MLF, PPRF, sixth nuclear zone and seventh fascicular zone; Figure 2A: MRI Brain - Sagittal section; Figure 2B: Diffusion weighted MRI Brain - Axial view.

contrast was done which showed evidence of acute infarct involving right posterior pons at medial longitudinal fasciculus and paramedian pontine reticular formation extending into abducens nuclear zone and $7^{\text {th }}$ nerve fascicular zone. Magnetic Resonance Angiogram brain showed aplasia of P1 segment of right Posterior cerebral artery and A1 segment of right Anterior cerebral artery Patient was referred to Neuro Physician where he was treated with antiplatelets and antihypertensives and patient was lost for follow-up further.

\section{DISCUSSION}

Eight and a half syndrome is due to a lesion in the dorsal tegmentum of caudal pons including the parapontine reticular formation, abducens nucleus, medial longitudinal fasciculus, and the nucleus and the fasciculus of the facial nerve. ${ }^{1}$ It comprises of internuclear ophthalmoplegia in addition to horizontal gaze palsy and ipsilateral lower motor neuron facial palsy. The ipsilateral eye cannot abduct or adduct and the contralateral eye can only abduct. On attempted lateral gaze away from the side of lesion the abducting eye 
overshoots the target giving rise to disconjugate nystagmus. The condition is often caused by a lesion (vascular or demyelinating) in the dorsal tegmentum of the caudal pons (BocosPortillo J et al, 2015). One and a half syndrome is usually caused by multiple sclerosis, infarcts, hemorrhages, trauma, basilar artery aneurysms, brainstem arterio-venous malformations and tumours. The involvement of the right Abducens nucleus, right MLF and right Facial fasciculus in the lower pontine tegmentum contributed to the observed clinical signs. Thus the recognition of this syndrome allows precise localization of the lesion in the lower pons. MRI Brain shows hyperintensity in lower pons at MLF, PPRF, abducent nucleus and facial fasciculus
(Sampath Kumar NS et al, 2014; Rosini F et al, 2013; Sarwal A et al, 2009) . Etiology attributed to lower pontine tegmental infarct is because of occlusion of right Paramedian pontine perforators (Kakar P et al, 2013).

\section{CONCLUSION}

It is very important to recognize the features of eight and half syndrome, in order to localize the lesion, and to determine the proper treatment regimen for which, the proper diagnostic examinations and investigations are required.

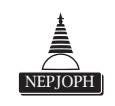

\section{REFERENCES}

Bocos-Portillo J, Ojeda JR, Gomez-Beldarrain M, Vazquez-Picon R, Garcia-Monco JC (2015). Eight-and-a-Half Syndrome. JAMA Neurol.;72(7):830. doi: 10.1001/jamaneurol.2015.0255; PMid:25962103

Eggenberger E (1998). Eight-and-a-half syndrome: one-and-a-half syndrome plus cranial nerve VII palsy.

J Neuroophthalmol;18(2):114-6. doi: 10.1023/A:1023294716282; PMid:9533655

Kakar P, Brown Z, Banerjee S (2013). Eight-and- a-half syndrome: an unusual presentation of brainstem infarction. QJM;106(3):273-6. doi: 10.1093/qjmed/hcr187; PMid:22011629

Rosini F, Pretegiani E, Guideri F, Cerase A, Rufa A (2013). Eight and a half syndrome with hemiparesis and hemihypesthesia: the nine syndrome? J Stroke Cerebrovasc Dis;22(8):e637-8. doi: 10.1016/j. jstrokecerebrovasdis.2013.01.018; PMid:23434442

Sampath Kumar NS, Raju CG, Kiran PR, Kumar TA, Gopal BV, Khaseem DB (2014). Eight-and-a-half syndrome: a rare presentation of pontine infarction. J Stroke Cerebrovasc Dis;23(8):e389-91. doi: 10.1016/j. jstrokecerebrovasdis.2014.01.002; PMid:24674953

Sarwal A, Garewal M, Sahota S, Sivaraman M (2009). Eight-and-a-half syndrome. J Neuroimaging;19(3):288-90. doi: 10.1111/j.1552-6569.2008.00261.x; PMid:18482369 